\title{
Correlation between the Fetal Liver Length and Crown- Rump Length During the First Trimester Screening
}

\author{
Erzat Toprak1, Murat Bozkurt², Yetkin Karasu³ \\ ${ }^{1}$ Department of Obstetrics and Gynecology, Başkent University Faculty of Medicine, Konya, Turkey \\ 2Department of Obstetrics and Gynecology, Kafkas University Faculty of Medicine, Kars, Turkey \\ ${ }^{3}$ Clinic of Obstetrics and Gynecology, Ankara Training and Research Hospital, Ankara, Turkey
}

\begin{abstract}
Objective: The aim of the present study was to determine the correlation between fetal liver length (FLL) at the 11+0-13+6 week of pregnancy and crown-rump length (CRL).

Methods: Pregnant women $(n=63)$ referring to the Başkent University Konya Hospital Obstetrics and Gynecology Clinic between January and March 2014 for first trimester screening were included in the study. Patients were excluded for the following reasons: two for type II DM, one for metabolic disease, and three because they refused to share their information. FLL was measured in patients at the 11+0-13+6 week of gestation and in those who had normal ultrasonographic findings. Exclusion criteria were as follows: nuchal translucency of $\geq 3.5 \mathrm{~mm}$, antenatal first trimester combined test results of $\geq 1 / 250$, reverse flow of the ductus venosus and tricuspid valve, absence of nasal bone (NB), and fetal malformation in second trimester. Fiftyseven women who fulfilled inclusion criteria were included in the study. Statistical Package for the Social Sciences version 15.0 (SPSS, Inc., Chicago, IL, USA) was used for statistical analysis. Descriptive statistics and Pearson's correlation test was used for correlation between FLL and CRL.

Results: Mean age of patients was $28.18 \pm 4.7$ (19-39). Mean gravida and parity were $2.05 \pm 1.2(1-6)$ and $1 \pm 0.8(0-5)$, respectively. Mean gestational age was 12.4 weeks (min: 11.1 - max: 13.6), and mean FLL of the study group was 11.2 $\pm 1.1 \mathrm{~mm}(8.2-13.7 \mathrm{~mm})$. Mean NT was $1.1 \pm 0.3(0.5-2.4) \mathrm{mm}$. In the present study, it was established that FLL was correlated with CRL ( $r(57)$ : 0.840; $p<0.001$ ).
\end{abstract}

Conclusion: This study showed that there was a significant, strong, positive correlation between FLL and CRL at the $11^{\text {th }}-13^{\text {th }}$ week of pregnancy. (JAREM 2015; 5: 60-3)

Keywords: Ultrasound, first trimester, fetal liver, liver length

\section{INTRODUCTION}

Although it is not a standardized part of fetal ultrasonography, measurement of fetal liver length (FLL) may be useful for the diagnosis of diseases such as Rh isoimmunization (1), hemoglobin Bart's disease (2), maternal diabetes (3), intrauterine growth retardation (4), twin-to-twin transfusion syndrome (TTTS) (5), and Down's syndrome (6). FLL is usually measured in the second or third trimester $(1,7)$. However, it is possible to measure FLL even at $7^{\text {th }}-9^{\text {th }}$ week of pregnancy (8). Crown-rump length (CRL), nuchal translucency (NT), nasal bone (NB), tricuspid valve (TV) regurgitation, and ductus venosus (DV) blood flow can be assessed in the second trimester ultrasound (9-12).

In the present study, we investigated the correlation between FLL and $C R L$ at $11+0-13+6$ gestational week of pregnancy.

\section{METHODS}

This prospective study included pregnant women admitted to the Başkent University Konya Hospital Obstetrics and Gynecology Clinic between January and March 2014 for the first trimester screening. Informed written and oral consents were obtained from all pregnant women participating in the study. The approval of the Ethics Committee was obtained from the Başkent University Faculty of Medicine.
Fetal liver length was measured in fetuses who had no anomaly in ultrasound scan and who had a CRL measurement of 45-84 $\mathrm{mm}$. Exclusion criteria were as follows: NT of $\geq 3.5 \mathrm{~mm}$; antenatal first trimester combined test results of $\geq 1 / 250$; reverse flow of the DV and TV; absence of NB; and fetal malformation in the second trimester. Sixty-three women who fulfilled inclusion criteria were included in the study.

All fetuses were measured for FLL on sagittal image using highresolution real-time ultrasound with a GE Voluson Pro V (GE Healthcare, Tiefenbach, Austria) $4-7-\mathrm{MHz}$ abdominal convex transducer (Figure 1).

In all cases, fetal CRL, NT, NB, tricuspid regurgitation, and DV blood flow wave were evaluated. FLL was measured in longitudinal axis from the dome of the diaphragm to the lower most point of the right lobe of the liver (Figure 1) $(1,7)$.

\section{Statistical Analysis}

Statistical Package for the Social Sciences version 15.0 (SPSS Inc., Chicago, IL, USA) was used for statistical analysis. Descriptive statistics and Pearson's Correlation test was used. A p value of $<0.05$ was considered statistically significant.

\section{RESULTS}

Two patients were excluded because of type II DM, one patient was excluded because of metabolic disease, and three patients 
were excluded because they refused to share their information. Therefore, there were 57 patients included in the study. Mean age of the patients was 28.18 \pm 4.7 (19-39) years. Mean gravida and parity were $2.05 \pm 1.2(1-6)$ and $1 \pm 0.8(80-5)$, respectively. Mean gestational age was 12.4 weeks (min: 11.1; max: 13.6), mean gestational age at delivery was $38.8 \pm 0.8(37.0-40.0)$ weeks, and mean birth weight was $3355 \pm 336$ (2700-3950) g. Mean NT was $1.1 \pm 0.3(0.5-2.4) \mathrm{mm}$. We summarized the ultrasonographic findings of the patients in Table 1. Mean FLL was measured as $11.2 \pm 1.1 \mathrm{~mm}(8.2-13.7 \mathrm{~mm})$. A scatter graph suggested that there may be a positive correlation between CRL and longitudinal FLL (Figure 1). Pearson's product moment revealed that there was a significant, strong, positive correlation between CRL and FLL, which accounted for $94 \%$ of the variance $r(57)$ : $0.840(p<0.001)$ (Figure 2).

\section{DISCUSSION}

This present study revealed that there was a significant, strong, positive correlation between $\mathrm{CRL}$ and $\mathrm{FLL}$, which accounted for $94 \%$ of the variance $r(57): 0.840(p<0.001)$. Similar to our study, Tongprasert et al. (13) reported that FLL increases as pregnancy progresses. They formulized this result as FLL $(\mathrm{mm})=1.61$ (GA, week) $-6.75(r(2)=0.94 ; p<0.001)$. Although it is not fully functional, still fetal liver plays a critical role in glucose, fat metabolism, and hematopoiesis during fetal development. It has both endocrine and metabolic functions. In this manner, fetal problems may affect fetal liver development even at early stages of the fetal development (13). Therefore, the evaluation of fetal liver may ensure early diagnosis of many diseases.

Morphologically, fetal liver is divided into four types: I. trapezoid (Type 1); II. triangular (Type 2); III. square (Type 3); and IV. rectangular (Type 4). Type III is the most common form. Size, weight, volume, and number of lobes are usually correlated with gestational age. Fetal liver acquires the characteristics of adult liver morphology at term (14).

Factors affecting FLL can be either physiologic or pathologic. It was reported that racial factors may play a role in the length of fetal liver $(7,15,16)$. Roberts et al. (3) showed that in diabetic pregnant women, the length of fetal liver is $12 \%$ longer than that in women with uncomplicated pregnancies. In addition, Roberts and Mitchell (5) established that in TTTS, fetal liver is larger in donor and recipient twins.

Hematopoiesis is divided into three periods in the embryo and fetus, which overlap. Mesoblastic, hepatic, and myeloid periods develop in the yolk sac, liver, and spleen and bone marrow, respectively. Hepatic period continues from $10^{\text {th }}$ week to $24^{\text {th }}$ week (17). Roberts et al. (1) demonstrated that in cases with Rh isoimmunization complicated by anemia, fetal liver is enlarged because of extramedullary hematopoiesis. Fetal liver assessment in isoimmunized patients may give some clue about the severity of the disease and the need for prompt intervention (transfusion or delivery) (16).

Down's syndrome is accompanied by fetal liver enlargement. In these cases, hepatomegaly usually is a result of hydrops and myleoproliferative diseases. Compared with the euploid fetuses, in
Table 1. Demographic characteristics and ultrasound findings of the patients $(n=57)$

\begin{tabular}{|l|c|}
\hline Patients parameters and results & \\
\hline Maternal age (year) & $28.18 \pm 4.7(19-39)^{\star}$ \\
\hline Gravidity & $2.05 \pm 1.2(1-6)^{\star}$ \\
\hline Parity & $0.8 \pm 1.0(0-5)^{\star}$ \\
\hline Gestational age (weeks) & $12.4 \pm 0.5(11.1-3.6)^{\star}$ \\
\hline CRL (crown-rump length) & $61.3 \pm 7.5(47-77)^{\star}$ \\
\hline Nuchal translucency (NT) & $1.1 \pm 0.3(0.5-2.4)^{\star}$ \\
\hline Fetal liver length & $11.2 \pm 1.1(8.2-13.7)^{\star}$ \\
\hline Delivery weeks & $38.8 \pm 0.8(37.0-40.0)^{*}$ \\
\hline Birth weights (gram) & $3355 \pm 336(2700-3950)^{\star}$ \\
\hline *: mean \pm SD (range) & \\
\hline
\end{tabular}

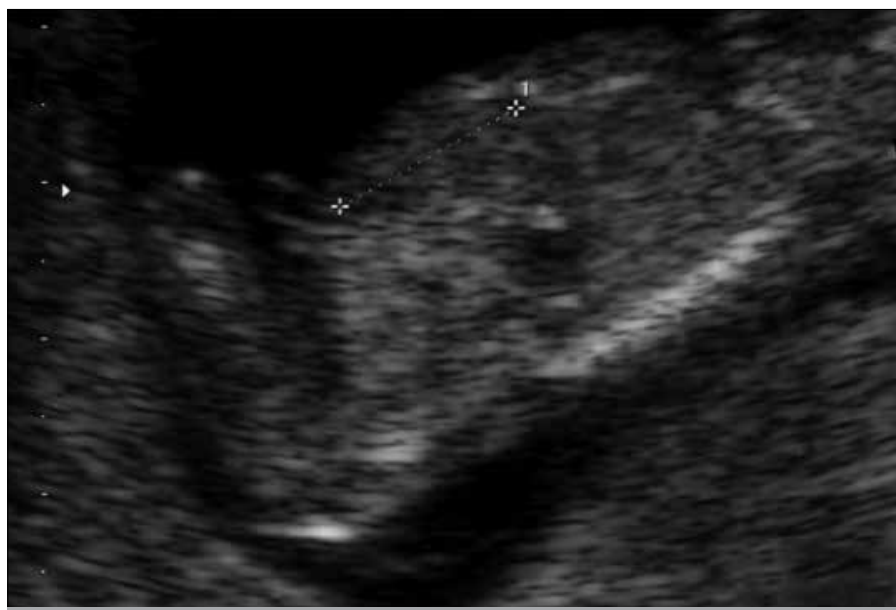

Figure 1. Measurement of Fetal liver lenght

trisomy 21 , there is no correlation between liver enlargement and NT, tricuspid failure, and abnormal DV blood flow (6).

Three-dimensional (3D) ultrasound can be used for fetal liver assessment. Although it requires more time, it has been shown that $3 \mathrm{D}$ fetal liver volume is also correlated with gestational age $(17,18)$.

There are some other diseases that may not affect the fetal liver diffusely. Focal fetal tumors or tumor-like diseases may also be diagnosed during the sonographic assessment of the fetal liver. Hemangiomas and mesenchymal hamartomas are the most commonly seen lesions during fetal development (19). In utero development of these lesions may also cause polyhydramniosis and fetal hydrops. Although they are rare, routine evaluation of the fetal liver in utero may also help the early diagnosis of these problems.

In another study, it has been shown that there is a strong correlation between FLL and OGTT results, with FLL possibly serving as a valid marker for the prediction of GDM in high-risk populations (20).

In the present study, it is suggested that FLL can be measured at the visit for second trimester Screening, and this measurement 


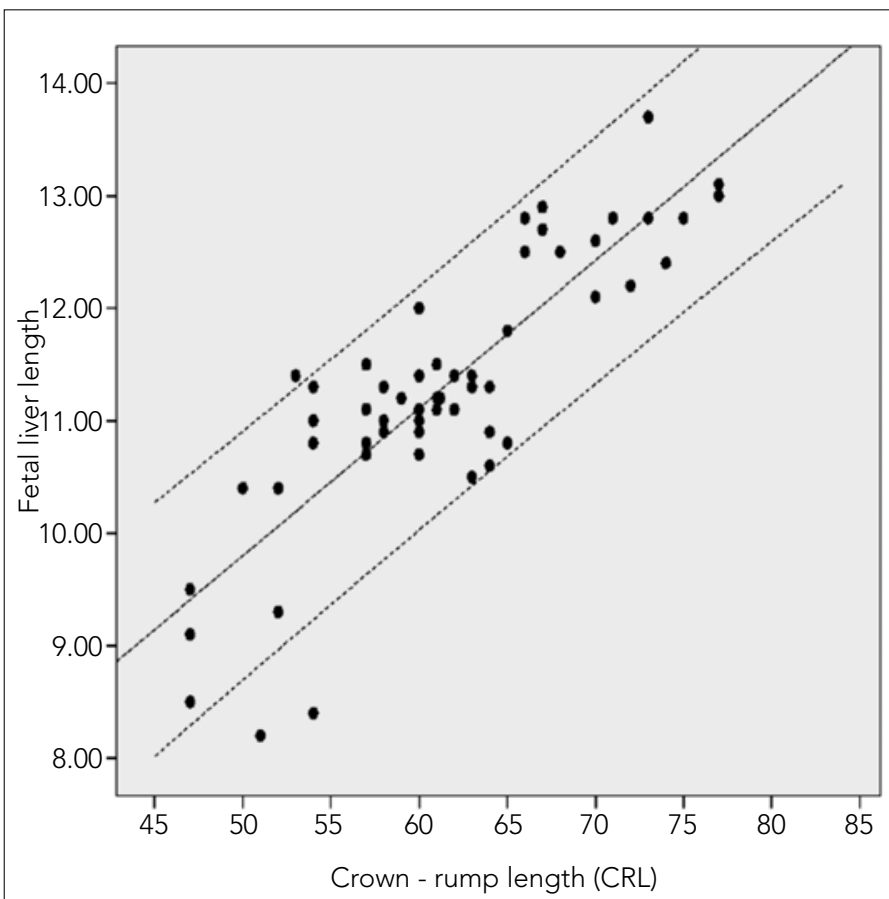

Figure 2. The correlation between fetal liver length and crown-rump length (The percantiles $50^{\text {th }}, 5^{\text {th }}$ and $95^{\text {th }}$ were showed)

was correlated with CRL. FLL measurement is important for the diagnosis of metabolic or chromosomal diseases accompanying liver impairment. FLL measurement is not difficult, and it can be standardized. We suggest that it is more difficult to evaluate NT because it is highly dependent on fetal position. Also, interobserver and intraobserver differences may affect NT measurement. Gestational diabetes is usually diagnosed in the second half of the pregnancy; FLL may give information about the prognosis of gestational diabetes. FLL measurement may be used for gestational age determination. In our opinion, the present study is important as a preliminary report for future studies working on these hypotheses.

\section{CONCLUSION}

Although relatively few number of cases may limit the power of this study, we suggest that in non-complicated pregnancies, there is a correlation between FLL and CRL measurement at $11^{\text {th }}$ $13^{\text {th }}$ gestational week.

Ethics Committee Approval: Ethics committee approval was received for this study from the ethics committee of Başkent University Faculty of Medicine.

Informed Consent: Written informed consent was obtained from patients who participated in this study.

Peer-review: Externally peer-reviewed.

Author Contributions: Concept - E.T., M.B.; Design - M.B., E.T., Y.K.; Supervision - E.T., M.B., Y.K.; Resource - E.T., M.B., Y.K.; Materials - E.T.; Data Collection and/or Processing - M.B., E.T., Y.K.; Analysis and/or Interpretation - M.B., E.T., Y.K.; Literature Review - M.B., Y.K.; Writer - M.B., E.T., Y.K.; Critical Review - M.B.
Acknowledgements: Authors would like to thank Assistane Professor, $\mathrm{H}$. Duygu Kara Bozkurt for English grammatical editing.

Conflict of Interest: No conflict of interest was declared by the authors.

Financial Disclosure: The authors declared that this study has received no financial support.

\section{REFERENCES}

1. Roberts $A B$, Mitchell JM, Pattison NS. Fetal liver length in normal and isoimmunized pregnancies. Am J Obstet Gynecol 1989; 161: 42-6. [CrossRef].

2. Tongsong T, Wanapirak C, Srisomboon J, Piyamongkol W, Sirichotiyakul S. Antenatal sonographic features of 100 alpha-thalassemia hydrops fetalis fetuses. J Clin Ultrasound 1996; 24: 73-7. [CrossRef]

3. Roberts AB, Mithcell J, Murphy C, Koya H, Cundy T. Fetal liver length in diabetic pregnancy. Am J Obstet Gynecol 1994; 170: 1308-12. [CrossRef]

4. Roberts AB, Mitchell JM, McCowan LM, Barker S. Ultrasonographic measurement of liver length in the small - for - gestational - age fetus. Am J Obstet Gynecol 1999; 180: 634-8. [CrossRef]

5. Roberts $A B$, Mitchell JM. Fetal liver lenth in twin - twin transfusion syndrome. Ultrasound Obstet Gynecol 1997; 9: 30-4. [CrossRef]

6. Gielchinsky Y, Zvanca M, Minekawa R, Persico N, Nicolaides KH. Liver volume in trisomy 21 and euploid fetuses at 11 to 13 weeks. Prenat Diagn 2011; 31: 28-32. [CrossRef]

7. Vintzileos AM, Neckles S, Campbell WA, Andreoli JW Jr, Kaplan BM, Nochimson DJ. Fetal liver ultrasound measurements during normal pregnancy. Obstet Gynecol 1985; 66: 477-80.

8. Hata T, Fujiwaki R, Senoh D, Hata K. Intrauterine sonographic assesments of embryonal liver length. Hum Reprod 1996; 11: 2758-61. [CrossRef]

9. Nicolaides KH, Azar G, Byrne D, Mansur C, Marks K. Fetal nuchal translucency: ultrasound screening for chromosomal defects in first trimester of pregnancy. BMJ 1992; 304: 867-9. [CrossRef]

10. Cicero S, Bindra R, Rembouskos G, Tripsanas C, Nicolaides KH. Fetal nasal bone length in chromosomally normal and abnormal fetuses at 11-14 weeks of gestation. J Matern Fetal Neonatal Med 2002; 11 : 400-2. [CrossRef]

11. Kagan KO, Valencia C, Livanos P, Wright D, Nicolaides KH. Tricuspid regurgitation in screening for trisomies 21,18 and 13 and Turner syndrome at $11+0-13+6$ weeks of gestation. Ultrasound Obstet Gynecol 2009; 33: 18-22. [CrossRef]

12. Toyama JM, Brizot ML, Liao AW, Lopes LM, Nomura RM, Saldanha FA, et al. Ductus venosus blood flow assesment at 11 to 14 weeks of gestation and fetal outcome. Ultrasound Obstet Gynecol 2004; 23 : 341-5 [CrossRef].

13. Tongprasert F, Srisupundit K, Luewan S, Tongsong T. Normal length of the fetal liver from 14 to 40 weeks of gestational age. J Clin Ultrasound. 2011; 39: 74-7.

14. Albay S, Malas MA, Cetin E, Cankara N, Karahan N. Development of the liver during the fetal period. Saudi Med J 2005; 26: 1710-5.

15. Murao F, Takamori H, Hata K, Hata T, Kitao M. Fetal liver measurements by ultrasonography. Int J Gynaecol Obstet 1987; 25: 381-5. [CrossRef]

16. Phatihattakorn C, Ruangvutilert P, Sansaneevithayakul P, Boriboonhirunsarn D. Reference centile chart for fetal liver length of Thai fetuses. J Med Assoc Thai 2004; 87: 750-4

17. Arbeille P, Fornage B, Boucher A, Ruiz J, Georgescu M, Blouin J, et al. Telesonography: virtual $3 \mathrm{D}$ image processing of remotely acquired abdominal, vascular, and fetal sonograms. J Clin Ultrasound 2014; 42: 67-73. [CrossRef] 
18. Chang FM, Hsu KF, Ko HC, Yao BL, Chang CH, Yu CH, et al. Threedimensional ultrasound assessment of fetal liver volume in normal pregnancy: a comparison of reproducibility with two-dimensional ultrasound and a search for a volume constant. Ultrasound Med Biol 1997; 23: 381-9. [CrossRef]
19. Makin E, Davenport M. Fetal and neonatal liver tumours. Early Hum Dev 2010; 86: 637-42. [CrossRef]

20. Perovic M, Gojnic M, Arsic B, Pantic I, Stefanovic T, Kovacevic G, et al. Relationship between mid-trimester ultrasound fetal liver length measurements and gestational diabetes mellitus. J Diabetes 2014 Aug 14. doi: 10.1111/1753-0407.12207. [CrossRef] 